\title{
The Micro-Blog Marketing Application Research in Taobao Shop
}

\author{
Chunpeng $\mathrm{Li}$ \\ School of Business and Information Technology \\ Quanzhou Normal University \\ Quanzhou, China \\ Chunpeng-li@163.com
}

\author{
Danjing Lin \\ School of Business and Information Technology \\ Quanzhou Normal University \\ Quanzhou, China \\ 649047197@qq.com
}

\begin{abstract}
Since 2010, the micro-blog as a new interactive platform is being more and more people of all ages. Many Taobao businesses use microblogging marketing to interact with consumers, promote their Taobao shop, selling their Taobao commodity. This paper describes the definition and a characteristic of microblogging marketing, analyzed and compared to other marketing model, and summarizes the important points value of micro-blog marketing Taobao shop. At the same time, combined with today's domestic micro-blog marketing application Taobao shop, analyze the current situation of the Taobao shop micro-blog marketing some problems, such as lack of professional bloggers, microblog content is boring, lack of target customers attention in and put forward corresponding recommendations, feasibility and constructive frame of reference Taobao business use micro-blog marketing decisions.
\end{abstract}

Keywords- micro-blog marketing; Taobao shop; microblog; Taobao business

\section{DEFINITION AND CHARACTERISTICS OF MicROBLOGGING MARKETING}

Microblogging marketing has just launched a network marketing model, as microblogging hot. It gave birth to the marketing, which is the marketing microblogging. Everyone can register a microblogging Sina, Sohu, Tencent, etc. Then through their own micro-blog, they updated daily content to interact with you to discuss all topics of interest, in order to achieve the purpose of marketing.

\section{A. The Definition of Marketing Microblogging}

Microblogging marketing is to make use of the microblogging platform, including brand promotion, event planning, the personal image packaging, product promotion, and so on a series of marketing activities.

\section{B. The Characteristics of Microblogging Marketing}

The microblogging can achieve the interaction between the merchant and the customer online long-distance customer's service. So that it can help customers solve the problem effectively. It is not only a success factor of microblogging, but also wins customer loyalty. In order to achieve close contact with customers and merchants, Taobao business network promote a new marketing model. As its high degree of openness between the Internet and mobile networks, the user is able to publish messages regardless of when and where. Compared to traditional marketing, microblogging marketing has the following characteristics:

1) Three-dimensional. Microblogging marketing can make use of advanced multimedia techniques, from the form of text, images, video shows the product description. So that consumers are more images directly receive information [1]. The network interactive interface allows visitors to read hierarchical information, which is not only conducive to the information recipient read the message. Disseminators of information are more conducive to take full advantage of the feedback. The effect achieved by different information develops a more acceptale the advertising strategy.

2) High-speed. One of Microbloggings most obvious features is its rapid spread. WAP The Internet and to make contact with the mobile phone WAP platform, a microblogging by all the relevant group will be able to spread to all corners of the world within a few minutes after the issue, a short period of time, most visitors have.

3) Convenience. Microblogging marketing is superior to the traditional means of communication industry. The release of information doesnt has to go through a cumbersome approval, thus saving a lot of time and cost. , Microblogging organizational requirements of the language are not as high as a blog. Users only need to respond to their own feelings, and does not need to be long-winded. It is also convenient to update. API Microblogging opened a variety of API and enables a large number of users through the mobile phone network to update their personal information.

4) Interactive. Microblogging has the Forum Website openness and interactivity of social networking sites. It does not need to verify the "concern" mechanism and comments, forwarding and other functions to the user to provide a good interactive platform. "The microblogging marketing of interactive first is reflected to consumers the chance to speak. Followed by feedback, can be tailored for a specific potential targets consumers personalized Internet marketing campaign, making the enterprise a more targeted and impersonal "[2]. Microblogging dissemination of information by the recipient at the same 
time, establish a one-to-one, one-to-many or many-tomany interaction interpersonal communication network between users.The ordinary users transcended the traditional media that can only passively accept the limitations of the information [3].

Based on the above advantages, the microblogging marketing as a means of network marketing have the advantage of network marketing. The marketing costs are lower than media advertising prices. Taobao business on the microblogging marketing is just a start. Microblogging is a good tool. It can help the business of Taobao arrived that not been discovered, and the level of potential customers. Customers already have to keep sticky contact. Taobao business is concerned. This is a new opportunity; it may Taobao business conditions at no cost to bring a large number of target customers. Taobao business does not understand the microblogging marketing, and do not grasp its characteristics.

\section{THE APPLICATION STATUS OF MiCROBLOGGING MARKETING TAOBAO SHOP}

Proportion of social media has published a variety of ecommerce website traffic origin, straight up. No one suspected the enormous potential of social media ecommerce site. Especially for e-commerce enterprises, microblogging marketing is part of network marketing, and they are more intimacy, more inherent advantages. In short, the shop microblogging promotion, compared to traditional SEO, ad networks, forums promotion of its low cost, easy to operate, dissemination of good features, no doubt has great appeal.

If we say in 2011, only a few Taobao shop try microblogging marketing, but in 2012, it will have more shop into microblogging direct marketing activities.

Sina Weibo microblogging Development Report "in the first half of 2012, the share of short-chain (a site of short-chain Share contains the Web site domain name short chain the original Bowen number) ranking can be seen Taobao accounted for by $9.8 \%$ in the first place. Click on the amount of short-chain (a short chain of hits of the site refers to the number of user clicks on the site of short-chain) Taobao ranked in the top $8.5 \%$. At the same time, the microblogging Development Report "in the first half of 2012, Taobao reflux ratio (a site reflux ratio is calculated as the reflux ratio $=981 \%$ of the site of the short-chain Clicks / the site of the short-chain share amount). The last six months, it seems that Taoao analyzed by Sina index maintained at about 20000-350000 hot.

Coincidence degree According to the "China Business News" reported: Sina Weibo Taobao users up to $45 \%$, Sina users within a week visit Taobao; Taobao users, $22 \%$ of people at the same time visited Sina Weibo.

According to Hitwise monitoring data show that, in October 2012, 8.6\% whereabouts of e-commerce and local informational sites, and the Sina microblogging external output flow. This part of the flow has high realizable value. At the same time, several large electronic business platforms are the most prominent of outbound traffic sites of Sina Weibo. Output flow by sina microblogging of Taobao is accounted for 2.8\%, and Lynx Mall0.9\%, Jingdong Mall 0.5\%.

Seems from the Alibaba Group, Taobao internal has been built very mature flow trading system. Alibaba platform shift in Taobao customers has joint sellers, media into a more successful ecosystem. More and more media into this platform is highly recognized by Taobao and Lynx seller. Taobao Sina microblogging traffic accounts for about $2.5 \%$, higher than the beautiful and mushrooms Street vertical the social electricity supplier media.

The above data show that more and more businesses use Taobao microblogging microblogging marketing platform., Through publish wonderful Bowen attractive activities, and to discuss the hot topic, increase the flow of Taobao shop to expand the publicity of the shop. The same time, these wonderful microblogging attractive activities attracted more fans and reviews, bring the amazing amount of sharing and hits.

\section{THE MAIN PROBLEMS OF TAOBAO SHOP MICROBLOGGING MARKETING}

\section{A. Micro-Bobo Main Lack of Expertise}

Microblogging is also an emerging platform. The bloggers contact microblogging short, a lack of some skills. Blogger is a core in microblogging. The bloggerss writing skills, literary skills, social hot topic of sensitivity, the ability to communicate with the fans impact on the quality of the micro-Bo, review the amount of forwarding.

The Taobao shop micro-Bobo, lack of expertise, lack of literary skills only shriveled language to describe and promote their products; people will think it is spam. The sensitivity of the main social hot topic of some Taobao shop micro-Bobo is not strong. They take the used topic to promote their own Taobao shop. Such kind of microblogging often can not be matter of public concern. Microblogging is also a consumer Taobao business communication platform, there will be some fans negative comments, some lack of communication skills, lower quality Taobao micro-Bobo Lord will acrimony, and does not handle these problems, which often may substantially dissipated the customer's attention.

\section{B. Description of the Micro-Bo Is Not Enough to Attract Users}

In a variety of content microblogging interface, microblogging content is the key to attract customer's attention. Wonderful Bowen may get the user's click, but boring Bowen only allows users to glimpse over.

We can see some boring micro-blog content everywhere. For example, some apparel the Taobao shop microblogging, blindly text: fabric, price, Taobao shop's website, no highlights, crumpled text to promote. Still we can use outdated topic to gain customers attention, such as when people talk about Apple phone, Steve Jobs. Some shop selling mobile phones related products is still stuck in Nokia. For these, we usually do not do too much attention. Dull micro-blog content will not be any good Taobao shop, 
but when the user pages are full of Taobao shop Products may also psychological boredom cancel microblogging concern.

\section{Microblogging Target Customers Is Not Clear}

With the rapid development of the network, microblogging has become the new darling of the people's social networking. Just two years, the development of micro-Bo throughout all corners of the country, more and more people become microblogging control. , In the end, what are our target customers is a difficult problem in these microblogging users.

Many Taobao business is also the author of the wonderful blog, fun activities, and the promotion was big enough, but a few months microblogging number of fans or very few, did not play a significant effect. Encountered such a problem, Taobao business home should consider the following questions: which are your target population groups? Where is your target population? The microblogging marketing method used is not to say that the more, the better. Do microblogging marketing through microblogging platform, Taobao business must first understand you target population, and the kind of method to achieve the best results? Taobao business family in the target population did not analyze their own microblogging blind publicity and promotion. This will not only spend a lot of time and effort, and to obtain the results are not good.

\section{Micro-Bo Fans Less Target Customers}

The attention of the microblogging marketing is a very important aspect of the microblogging marketing to be successful. Fans of concern are essential. It will be possible to promote Taobao shop, promotional Taobao brand, increasing shop visits through comments by fans.

But some bloggers are not professional enough, in itself a lack of sensitivity to the market. A lot of people do not want to pay attention to this micro-Bo. It can not be very limited attention in the crowd, accurately determine the target customers. These factors are exacerbated by a reduction in the degree of concern of microblogging. The impact of the implementation of the microblogging is marketing plan. Concerned about the lack of target customers, comments and forwarding number is getting lower and lower. Before long, the Taobao shop microblogging will have no effect.

\section{TAOBAO SHOP TO CARRY OUT THE} RECOMMENDATIONS OF THE MARKETING MICROBLOGGING

\section{A. Improve Micro-Bobo Main Professional}

Micro-Bobo Lord is the core of a micro-Bo, bloggers writing skills, literary skills, social hot topics sensitivity and ability to communicate with the fans.

Taobao shop decided to do microblogging marketing, constantly improve their professional. Microblogging bloggers must have good writing skills. In the promotional of products will not make the reader bored but also to generate interest. At the same time, it has a keen insight into the hot spots of society, often posted on the microblogging certain hot topic of concern to attract large number of fans. After the accumulation of a certain number of fans, build their own fan base. On this basis, to promote their own Taobao shop and product, their fans will be very easy to see that businesses will be able to target customers through the microblogging Taobao shop. In order to drive the development of the Taobao shop microblogging, the main micro-Bobo needs to upgrade their skills.

\section{B. Make the Micro-Bo Description Attractive}

Microblogging social media as a social recognition before the establishment of the network of mutual concern, the customer is concerned about your premise. He felt can be obtained from the shop microblogging value; this value may be for your Taobao shop brand recognition, perhaps products and services like it, or the appreciation of your micro-blog content. If the customers are mostly women, the contents of the micro-Bo can write how beauty loses weight, make-up shopping, in conjunction with their own shop products and URL. If the customers are mostly men, the microblogging can contain some Heung Che beauty, promotion and pay rise, political news, in conjunction with their products and Taobao site. All in all, so that customers felt microblogging content is valuable on their own.

\section{Identify the Precise User on the Microblogging}

1) Label to find user. Microblogging users will accord to their characteristics or preferences for their own microblogging different labels affixed. According to the characteristics of these fans, they age, status, we can classify occupation, hobbies and other aspects. If our goal is just coincidence and a certain type of crowd, this type of microblogging users will be our target users, and also we need to guide the people [4].

2) To find the user by topic. Through the the topic name of micro-blog, the biggest advantage is that we can search to find the crowd involved in a topic directly through the microblogging. NBA If you find that some users are often involved in the NBA, football discuss this topic, Taobao shop happens to sell sports products that microblogging users is your target user.

3) Find the user through the micro-group. QQ Microgroups like QQ group are a group of people who gathered together because a common feature or topic to communicate and interact. If the main topic of the microgroup and your product more closely integrated, users of the micro-group are your target users.

4) To enhance the popularity of microblogging in the target user

a) Pay close attention to user who follows you actively: If the shop microblogging have some quality content, which customers like to watch, and then the next thing is to attract them to your micro-blog. It is a good idea to give interest in your target audience. The average 
user in getting new attention will pay a return visit to each other's microblogging to see what the new fans published.

b) Forwarding and comment on the user's information:Not all users will pay a return visit or each powder their new fans; we need to take the initiative in this case. Often forwarded to the user's micro-blog, write something of value and forwards at the same time, indepth reviews with shop link at the same time, not a few will be the user's attention. Users will feel that they are respected, they published someone to appreciate, but it is to find like-minded friends. In this case, your fans give an active interest in you will be a natural thing [5].

c) Concentration of micro-groups in the target user actively interact: Micro-groups provide a place around the exchange and discussion of a topic; group members are often concerned about this topic. If we can often send some users concerned content, group discussions and exchange, can help users to solve the problems. Then the users within the group will change into our fans slowly.

\section{ACKNOWLEDGMENT}

This research was supported by the funds from: Foundation item 1: Fujian university key project construction service routines "A Study on the Development of Regional Economies in Southern Fujian Province ", Project Number: B054; Foundation item 2: Science Plan Project of Quanzhou, Project Number: 2012Z109, 2012Z124; Foundation item 3: Science Plan Project of Fujian "Research of cycle development mode of Fujian agricultural processing industry - Quanzhou for Example".

\section{REFERENCES}

[1] Xin Qing Hong enterprise microblogging marketing value and Strategy [J]. Market Modernization, 2011 (20):46-47. (in Chinese)

[2] Xueming Li microblogging marketing: how to impress consumers [J]. The young reporter ,2011,26:61-62. (in Chinese)

[3] Maureen micro-blog, big impact [J]. Strait Science ,2011,04:53-54 +65 . (in Chinese)

[4] Wang Yubo SME the microblogging marketing analysis [J]. Marketing strategy, 2012 (01):40-41. (in Chinese)

[5] Liu Jie, Zhang Xi, a microblogging marketing incentives [J]. Vitality of enterprises, 2011 (08):38-40. (in Chinese) 